\title{
ORIENTAÇÃo de eNFERMAGEM NA AUTO-APLICAÇÃO DE INSULINA
}

* Maria Helena Machado

* Márcia Caron-Ruffino

** Maria Aparecida Bonfim

\begin{tabular}{l|l}
\cline { 2 - 2 } & $\mathrm{RBEn} / 04$ \\
\hline
\end{tabular}

MACHADO, M.H. - Orientaçāo de enfermagem na auto-aplicaçāo de insulina. Rev. Bras. Enf.; DF, 32 : 167-171, 1979.

\section{I - INTRODUÇĀO}

O emprego da insulina está sujeito a acidentes podendo dar origem a complicações, e sabemos que com um ensinamento adequado ao paciente, poderemos evitar alguns tipos dessas complicações que achamos oportuno recordar, assim:

A formaçāo de abcessos por injeções de insulina, cuja incidência é baixa. Poucos pacientes, com efeito, assinalam a ocorrência de um ou mais abcessos causados por injeçāo de insulina. apesar de dezenas de anos de uso do hormônio. E supreendente tal fato, tendo em conta que nem sempre são tomados os devidos cuidados de assepsia durante as injeções (ARDUfNO, 1973).

A lipodistrofia insulínica, que, se forma na gordura subcutânea nos pontos onde o hormônio é repetidamente injetado. A lesāo resultante recebeu o nome genérico de lipodistrofia insulínica comportando dois tipos: - reduçāo ou desaparecimento local da gordura do tecido subcutâneo e - aumento da deposição de gordura nas áreas de injeção do hormônio, caracterizando a lipo-atrofia e lipo-hipertrofia.

A incidência da lipodistrofia registrada por diferentes autores é bastante variável, o que em grande parte, resulta da cuidadosa observaçāo dos pacientes. Pode ocorrer com qualquer dos tipos de insulina empregada, diabéticos jovens são os mais propensos ao desenvolvimento de lesāo, podendo entretanto, surgir em qualquer idade. Parece desempenhar papel de importância na instalaçāo da lipodistrofia, pois no adulto, praticamente ela só incide no sexo feminino, ao passo que na puberdade, ambos os sexos podem ser igualmente

* Docentes da Escola de Enfermagem de Ribeirāo Preto, da Universidade de São Paulo.

* Enfermeira da Unidade de Internação de Clínica Médica do Hospital das Clínicas da Faculdade de Medicina de Ribeirão Preto. 
MACHADO, M.H. - Orientação de enfermagem na auto-aplicação de insulina. Rev. Bras. Enf.; DF, 32 : 167-171, 1979.

afetados. Doses elevadas de insulina: não são pré-requisitos essenciais ao seu desenvolvimento. A lipodistrofia tanto pode aparecer algumas semanas após o inicio do uso da insulina, quanto apenas se manifestar muitos anos depois. Os pacientes geralmente só percebem a existência da lesão quando esta já. alcançou certo vulto, chamando atenção a forma atrófica.

$\mathrm{Na}$ maioria dos casos, as lesōes se localizam nas áreas onde a insulina é reiteradamente injetada (coxas, nádegas, braços, abdomen), às vezes se desenvolvem nas proximidades dessas áreas e mesmo à distância. Além disso, embora habitualmente as deformaçōes sejam ou do tipo atrófico ou do tipo hipertrófico, podem as duas lesões coexistirem ou se alternarem no mesmo paciente.

A lipoatrofia tem início progressivo e se apresenta como depressōes de extensão e profundidade variáveis, desde pequenas placas que podem passar despercebidas, até amplas e profundas escavaçōes deformantes.

As lesōes de lipohipertrofia insulínica se apresentam como elevaçōes ou tumores arredondados, indolores, bem delimitados ou difusos, oferecendo a consistência de tecido adiposo. Por serem indolores esta forma é menos percebida pelos pacientes que a lipoatrofia. E sendo uma região cuja sensibilidade é menor, os pacientes procuram nela aplicar a injeção, agravando a lesão.

Válrias sugestōes foram oferecidas para explicar a ocorrência da lipodistrofia insulínica. Desde trauma mecânico repetido pela agulha, irritação pelo álcool usado na assepsia até a injeção de insulina gelada. A explicação mais aceita é a que foi demonstrada por RENOLD, 1950, em ratos, é a de que a lipodistrofia resulte da ação local, da própria insulina, uma vez que existe um aumento individual das células adiposas no local onde a insulina é injetada.
Em se aceitando uma ação direta local da insulina na gênese da lipodistrofia, não se tem explicação nos casos em que a lesão surge em áreas próximas ou afastadas do ponto de aplicação do hormônio. Outra dúvida também permanece que é a influência do sexo na incidência da lipodistrofia. Não se poderia aceitar que nos adultos, a incidência quase que na maioria total dos casos de lesão incida no sexo feminino devido a um maior desenvolvimento do tecido adiposo na mulher.

As deformaçōes oriundas da lipoatrofia trazem às vezes sérios problemas psicológicos que podem interferir até no controle do diabete. Como essa complicação é de difícil solução o melhor seria que estivéssemos atentos para prevenir tais complicaçōes evitando injetar a insulina num mesmo ponto, senão com intervalos de pelo menos um mês. Para isso, é mister fazer amplo mapeamento da superfície cutânea e seguir um rotelro na aplicação do hormônio, de sorte a nunca aplicar uma injeção à distância inferior a $2 \mathrm{~cm}$. da plcada anterior. (ARDUINO, 1973).

Deste modo, para a profilaxia dessa lesão, o conhecimento e observação desses aspectos pela enfermeira são lmportantes no cuidado do paciente. Sabemos que existem outros tipos de complicações como a hipoglicemia, a alergia e a resistência à insulina, porém estas não estão relacionadas com a técnica de aplicação.

BEASER, 1956; KRYSAN, 1965; ARDUINO, 1932; enfatizam a necessidade de ser iniciada pela enfermeira tão logo seja possivel a orientação dos pacientes diabéticos recém-admitidos.

ARDUíNO, 1962, refere que entre as causas do paciente diabético sofrer impacto emocional ao tomar conhecimento do diagnóstico da doença é o uso permanente da insulina.

MENDES, 1975, refere que $90 \%$ dos pacientes do sexo masculino que auto- 
MACHADO, M.H. - Orientação de enfermagem na auto-aplicação de insulina. Rev. Bras. Enf.; DF, 32 : 167-171, 1979.

administravam insulina e $94 \%$ do sexo feminino cometeram erros de dosagem. A autora comenta: "sobre a necessidade de ser enfatizado o ensino aos pacientes no que diz respeito à autoadministração da insulina; devendo ser considerado que o paciente que se submete à administração deste medicamento por várias pessoas pode estar mais sujeito a erros do que quando ele próprio é o responsável por esse cuidado".

"Não é justo exigir a cooperação permanente e acertada do paciente se este não se encontrar esclarecido sobre os motivos das medidas que lhe são aconselhadas e se não estiver a par das consequiências que diz respeito às prescriçōes do médico podem acarretar". ARDUINO, 1962.

Segundo dados fornecidos pelo Hospital das Clínicas de Ribeirão Preto, em 1976, através do CPDH (Centro de Processamento de Dados Hospitalares), internaram-se com diagnóstico principal de "Diabete Mellitus", 68 pacientes e com diagnóstico secundário, 97 pacientes, com uma duração média de internação de 21,7 dias.

Em 1977, internaram-se 58 pacientes com diagnóstico secundário, $76 \mathrm{pa-}$ cientes, com uma duraçāo média de internação de 21,7 dias.

RAMOS, 1976, recomenda que enfermeiros participem de cursos que preparem profissionais de equipe de saúde para o ensino aos pacientes, e, que as Escolas de Enfermagem propiciem às estudantes de enfermagem a oportunidade de planejar, desenvolver e avaliar a orientação a pacientes diabéticos. Essa recomendação aceita e divulgada no XXVIII Congresso Brasileiro de Enfermagem vem reforçar nossa responsabilidade em identificar as necessidades de enfermagem de maneira a assegurar uma assistência adequada aos pacientes.
Baseadas nessas recomendaçōes, as autoras se propuseram a levar a efeito a orientaçāo sistemática dos pacientes diabéticos quanto à aplícação de insulina, visando através deste relato, intensificar e aprimorar a atenção de enfermagem nesses aspectos.

\section{II - MATERIAL E MÉTODO}

Foram orientados pacientes diabéticos que se internaram na Clínica Médica do Hospital das Clínicas de Ribeirão Preto. Preliminarmente era examinado o prontuário do paciente a fim de ser verificada a prescrição de insulina e se o mesmo já tinha sido internado outras vezes para tartamento.

Seguiram-se quatro fases ou passos, a saber:

\section{PASSO:}

Entrevista com o paciente, onde foi investigado o que o paciente sabia sobre seu diagnóstico e tratamento. Se percebido receptividade por parte do paciente, continuava-se indagando quanto an tempo do uso da insulina - tipo da mesma - quem aplicava. A percepção visual e escolaridade, condição sócioeconômica também foram investigadas, assim como a observaçāo da integridade física do paciente e suas condições emocionais. (ANEXO).

\section{PASSO:}

Procedeu-se a realização de palestras com os pacientes sobre sinais e sintomas de diabete e importância de sua participação no tratamento da mesma.

\section{PASSO:}

Quando se percebia estar o paciente apto, fazia-se o convite para o mesmo participar da orientação da autoaplicação da insulina. Se aceito o convite passava-se para o $3 .^{\circ}$ passo de demonstração e ou explicação ao paciente quanto à desinfecção de seringa, obser- 
MACHADO, M.H. - Orientação de enfermagem na auto-aplicação de insulina. Rev. Bras. Enf.; DF, 32 : 167-171, 1979.

vação de dosagem, preparo da medicação quanto ao local de aplicação.

Material usado para demonstração: seringa, agulhas, frascos de insulina, algodão, panela, garfo (para retirar o material esterilizado).

\section{4. ${ }^{\circ}$ PASSO:}

Quando o paciente respondesse satisfatoriamente as questões, passava-se para o $4 .^{\circ}$ passo, que constou da autoaplicação de insulina.

Esse procedimento do paciente até a sua alta, foi supervisionado todas as vezes em que havia prescrição de insulina. Todos os passos foram executados para o paciente tantas vezes quanto o necessário. Foram elaboradas questões com o objetivo de avaliar o aproveitamento das palestras e demonstrações.

$O$ paciente era orientado para a alta, nos seguintes aspectos:

- Como proceder no domicílio;

- Importância do rodízio na autoaplicação de insulina;

- O significado da dieta e exercício;

- Retorno ao ambulatório, entrevista com enfermeira responsável pela orientação em ambulatório (onde serão reforçadas as orientações) ;

- Trazer sempre consigo o cartão que o identifica como "diabético" e com a especificação do tipo de insulina que faz uso.

\section{III - COMENTÁRIOS E RECOMENDAÇŌES}

Até o presente momento, o número de pacientes submetidos a tal orientação foi de 20, considerando-se não ser um número que forneça elementos para uma avaliação.

Alguns pacientes rejeitaram a idéia da orientação alegando ter quem lhes fizesse a aplicação. Essa rejeição pode- ria ser ainda ditada por inúmeros motivos, tais como: falta de interesse, medo, ansiedade, etc. Outros não foram treinados por apresentarem alguma condição que o impedisse, tais como: percepção visual deficiente, não saberem ler, etc.

Recomendamos que para suprir essas faltas, sejam:

a) encaminhados para o ambulató-rio de of talmologia;

b) familiares serem convidados para entrevista a fim de ser estudado quem poderia se encarregar de receber a orientação;

c) averiguação de condições sócioeconômicas.

O relato dessa experiência e os dados acima reforçam a necessidade da orientação que continuará sendo feita através de um programa em cujo planejamento deverão participar outros elementos da equipe de saúde.

A orientação de enfermagem na auto-aplicação de insulina é viável e necessária.

No histórico de enfermagem a entrevista com o paciente diabético deveria ser dirigida com diálogo e observação que permitissem a elaboração de um plano de cuidados específicos. Então uma cuidadosa investigação quanto às necessidades sentidas pelo paciente deveria ser realizada, o que poderia ser levado a efeito através do processo de enfermagem.

\section{IV - BIBLIOGRAFIA}

ARDUiNo, F. e col. - Tratamento do Diabetes Mellitus - Atheneu, Rio de Janeiro, 1962.

ARDUINO, F. - Diabetes Mellitus e suas complicacões, 2. ${ }^{a}$ edição. Editora Guanabara Koogan, 1973.

CPDH - Centrn de Processamento de Dadns Hospitalares, Departamento de Medicina Social - Faculdade de Medicina de Ribeirão Preto, USP (mi- 
MACHADO, M.H. - Orientação de enfermagem na auto-aplicação de insulina. Rev. Bras. Enf.; DF, 32 : 167-171, 1979.

meografado), Publicaçāo Trimestral 1976 a 1977.

BEAZER, S. B. - Teaching the diabetic patient diabetes, 5 (2): 146-149, 1956.

KRYSAN, G. S. - How do we teach four million diabetics? - Amer. J. Nurs. 65 (11): 105-107, 1956.

MENDES, I. A. C. - Observaçāo da Administração de Insulina em Pacientes Diabéticos no Domicilio. Dissertaçāo de Mestrado, Escola de Enfermagem Ana Nery, UFRJ. 1975.

RAMOS, S. M. - Necessidade de orientaçāo à saúde do paciente diabético. Revista Brasileira de Enfermagem, D. F. 29 (4): 38-41, 1976.

RENOLD, A. E.; MARBLE, A. e FAWCETT, D. W. - Action of insulin of glicogen and storage of fat in adipose tissue. Endocrinology, 46:55, 1950.

\section{UNIVERSIDADE DE SÃO PAULO ESCOLA DE ENFERMAGEM DE RIBEIRÃO PRETO DEPARTAMENTO DE ENFERMAGEM GERAL E ESPECIALIZADA}

\section{HISTÓRICO DE ENFERMAGEM}

\section{ORIENTAÇÃO DE ENFERMAGEM NA AUTO APLICAÇAO DE INSU'LINA}

DATA: ................

NOME:

ENF.:

ESTADO CIVIL
ENFERMEIRA:

REG.

IDADE:

SEXO:

Recursos da comunidade (para aplicar insulina)

Conhecimento do diagnóstico médico:

Tipo de insulina prescrito:

Onde adquire:

Custo:

Quem aplica:

Estado psicológico:

Percepção visual:

Condições da pele:

Dieta (o que estava comendo em casa):

O que gostaria de saber?:

Tem alguma coisa para dizer?:

Poderíamos ajudar em alguma coisa?:

Como recebeu o convite para aprender a auto aplicação?:

Observação do entrevistador:

Demonstração (n. ${ }^{\circ}$ de vezes) :

Material usado:

Técnica:

Devolução: 